\title{
Surface protein p104 is involved in adhesion of Listeria monocytogenes to human intestinal cell line, Caco-2
}

\author{
V. K. PANDIRIPALLY, D. G. WESTBROOK, G. R. SUNKI and A. K. BHUNIA \\ Food Microbiology and Immunochemistry Laboratory, Department of Life Sciences, Alabama A \& M \\ University, PO Box 264, Normal, AL 35762, USA
}

\begin{abstract}
Adhesion of Listeria monocytogenes to intestinal endothelial cells is an important initial event in the pathogenesis of infection which is not well understood. The suggestion has been made that some proteins, including internalin and actin polymerisation protein (ActA), and carbohydrate molecules mediate, at least in part, the adhesion of listeria to certain cultured mammalian cells. This study investigated the role of a $L$. monocytogenes cell-surface protein of $104 \mathrm{kDa}$ (p104) in adhesion to human intestinal enterocyte-like Caco-2 cell lines by transposon (Tn916) mutagenesis and a p104-specific monoclonal antibody (MAb-H7). Genotypic and phenotypic characteristics of Tn916-transformed $L$. monocytogenes strains, AAMU530 and AAMU572, revealed that these strains did not express p104, and the transposon had been inserted at a single locus in the structural gene. Strains AAMU530 and AAMU572 yielded only 10 and $6.3 \%$ adhesion to Caco-2 cells. Coating of $L$. monocytogenes and $L$. innocua wild-type strains with MAb-H7 reduced adhesion to Caco-2 cells from $100 \%$ to 50 and $45 \%$, respectively, whereas on isotype control MAb EM-7G1 had no effect. Western blot analysis with MAb-H7 indicated that p104 is present in all Listeria spp. except in L. grayi. Furthermore, p104 is also present in internalin (BUG8) and ActA (LUT12) deficient strains, suggesting that p104 is indeed different from internalin or ActA proteins. Cytotoxicity analysis of strains AAMU530 and AAMU572 demonstrated that these strains, although haemolytic and phospholipase-positive, were avirulent when tested with a hybridoma B-lymphocyte cell line. Loss of virulence could be attributed to the interruption of adhesion of mutant strains to the hybridoma cell line. These results strongly suggest that p104 is an adhesion factor in $L$. monocytogenes and possibly in other Listeria species and is involved in adhesion to intestinal cells.
\end{abstract}

\section{Introduction}

Listeria monocytogenes, a food-borne human pathogen, is responsible for infections such as septicaemia and meningitis in immunocompromised individuals and is one cause of abortion in pregnant women [1]. A recent report indicated that $L$. monocytogenes also causes gastro-enteritis in healthy individuals [2]. Transmission in man is frequently linked to food contaminated by listeria and entry into the host normally occurs in the gut. In animal studies (following intragastric inoculation) bacteria pass the gastrointestinal barrier and possibly penetrate the intestinal epithelial cells over-

Received 24 Feb. 1998; accepted 4 May 1998.

Corresponding author: Dr A. K. Bhunia, Purdue University, Department of Food Science, West Lafayette, IN 479071160, USA. E-mail: bhuniaa@foodsci.purdue.edu laying Peyer's patches $[3,4]$. The organism then disseminates to the brain and to the spleen, liver and other lymphatic systems.

A key aspect of the pathogenicity of L. monocytogenes is its ability to invade and multiply in phagocytic and non-phagocytic cells. Adhesion of $L$. monocytogenes to host cells is an essential event for invasion leading to infection. Adhesion is presumed to be mediated by $L$. monocytogenes cell-surface molecules with complementary receptors present on the eukaryotic cells [5]. Internalin $(80 \mathrm{kDa})[6,7]$, actin polymerisation protein (ActA, $90 \mathrm{kDa}$ ) [8], and other surface molecules $[5,9,10]$ of $L$. monocytogenes have been shown to be partially responsible for adhesion to mammalian cells. Internalin A (In1A) is essential for entry into human enterocyte-like Caco- 2 cells, whereas Internalin $\mathrm{B}(\mathrm{In} 1 \mathrm{~B})$ is required for entry into cultured 
hepatocytes such as TIB73 and HepG-2 and some epithelial cell lines including HeLa, HEp-2 and Vero cells [11]. The cellular receptor for In1A has been shown to be the adhesion molecule E-cadherin [12], but the interaction between In1A and E-cadherin leading to bacterial uptake by the host cells is not yet understood. A third member of the internalin family, named In $1 \mathrm{C}$, has recently been identified [13] and has been reported to encode a secreted protein of 297 amino acids that is homologous to InlA and In1B. In1C possibly plays a role in the late stage of infection rather than in the uptake of $L$. monocytogenes by non-phagocytic cells [7]. Another surface protein of $60 \mathrm{kDa}(\mathrm{p} 60)$ present in all Listeria spp. has been reported to help $L$. monocytogenes to adhere and enter into mouse fibroblast (3T6) cell lines [14]. This protein apparently does not play any role in adherence or entry into Caco-2 cells $[14,15]$.

Several studies indicate that $L$. monocytogenes induces its own entry by initiating an 'internalisation signal' to the host cells to re-arrange cytoskeletal structure, thus allowing $L$. monocytogenes entry $[16,17]$. Attachment of $L$. monocytogenes also causes tyrosine phosphorylation of host cell mitogen-activated protein kinase (MAP) which facilities the internalisation process. Addition of protein kinase inhibitors, such as genistein, prevents L. monocytogenes internalisation; however, the MAP inhibitor does not inhibit bacterial adhesion to epithelial cells $[16,17]$.

In spite of extensive research on the pathogenesis of L. monocytogenes infection, adhesion of this organism to mammalian cells and tissues is poorly understood. The internalin and ActA molecules mentioned above are present only in L. monocytogenes and may be partly involved in adhesion to mammalian cells. However, reports by Meyer et al. [18] and Bunduki et al. [19] indicated that not only L. monocytogenes, but also $L$. innocua, $L$. seeligeri, $L$. ivanovii and $L$. welshimeri adhere to the primary intestinal endothelial cells. These studies suggested that there might be additional factors involved in adhesion of Listeria spp. to intestinal cells. In a preliminary report it was observed that L. monocytogenes, $L$. innocua and $L$. welshimeri also bind to Caco-2 and murine Blymphocyte (Ped-2E9) cell lines [20]. Addition of a monoclonal antibody $(\mathrm{MAb})$ raised against a surface protein of $104 \mathrm{kDa}$ (p104) partially blocked the adhesion of Listeria to Caco-2 and Ped-2E9 cells [20].

In this study, the role of p104 in L. monocytogenes was examined by the employment of transposon mutagenesis $(\operatorname{Tn} 916)$. Transconjugants deficient in p104 were studied for their ability to adhere to Caco- 2 cells. In addition, MAbs were used to study the adhesion of listeria to Caco-2 cells and to characterise p104 protein from various Listeria spp. Furthermore, the cytotoxicity of mutant strains $(\Delta p 104: \operatorname{Tn} 916)$ was evaluated in a tissue culture model [21].

\section{Materials and methods}

\section{Mammalian cells}

Human enterocyte-like Caco-2 (TIB37, ATCC) and murine hybridoma Ped-2E9 [21] cell lines were maintained in Dulbecco's Modified Eagle's Medium (DMEM) supplemented with fetal bovine serum (Atlanta Biologicals, Norcross, GA) $10 \%$ and glutamine $1 \%$ and incubated at $37^{\circ} \mathrm{C}$ in air with $\mathrm{CO}_{2} 7 \%$ under humidified conditions.

\section{MAbs}

MAb-H7, specific for the p104 surface protein of Listeria spp., was developed by immunising mice with heat-killed L. monocytogenes cells [20]. MAb EM$7 \mathrm{Gl}$, specific for a $66-\mathrm{kDa}$ cell surface protein of $L$. monocytogenes, was used in this study as a reference antibody [22]. Both MAbs (isotype IgG1) were purified by ammonium sulphate precipitation, followed by gel filtration chromatography (Sephacryl S-200). Protein concentrations were determined spectrophotometrically (absorption at $280 \mathrm{~nm} / 1.4 \times$ dilution factor) and concentrations for both antibodies were adjusted to $34 \mathrm{mg} / \mathrm{ml}$.

\section{Bacterial strains and transposon mutagenesis}

L. monocytogenes F4244 (WT), BUG8 ( $\Delta$ inlAB),

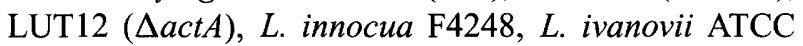
19119, L. welshimeri ATCC 35897, L. seeligeri SE31 and L. grayi ATCC 19120 strains were grown in brain heart infusion (BHI) broth with or without antibiotics. Escherichia coli CG120 carrying plasmid pAM120, which contains the transposon $\operatorname{Tn} 916$ [23], was used in this study. Conjugation of recipient strain L. monocytogenes $\mathrm{F} 4244$, erythromycin resistant $\left(\mathrm{em}^{\mathrm{r}}\right)$ and donor strain Enterococcus faecalis CG110, tetracycline resistant (tet ${ }^{\mathrm{r}}$ ) carrying $\mathrm{Tn} 916$ was accomplished by the procedure described by Kathariou et al. [24]. Transconjugant colonies from agar plates were transferred to nitrocellulose membranes and immunoprobed with MAb-H7 [20]. Mutants that showed weak or no reaction were selected and confirmed biochemically with API Listeria strips (bioMerieux, Hazelwood, MO, USA). Cultures were also tested for phospholipase $\mathrm{C}$ (PLC) activity on agarose $2 \%$ medium containing egg-yolk $7 \%, 50 \mathrm{mM} \mathrm{CaCl} 2$ and $50 \mathrm{mM}$ dithiothreitol [25]; and for listeriolysin (LLO) activity on sheep blood 5\% agar plates. Two mutant strains of L. monocytogenes, AAMU530 and AAMU572, were positive for PLC and LLO and were selected for further studies.

\section{Genetic analysis of transconjugants}

Plasmid (pAM120) carrying the Tn916 sequence was isolated from $E$ coli CG120 by the modified alkaline lysis or Quantum Prep Plasmid Miniprep (BioRad, Hercules, CA, USA) methods. Chromosomal DNA 
was prepared with GES reagent (5 M guanidine isothiocyanate, $0.1 \mathrm{M}$ EDTA, Sarkosyl $0.5 \% \mathrm{v} / \mathrm{v}$ ) followed by purification with the Wizard Genomic DNA kit (Promega, Madison, WI, USA). Chromosomal and plasmid DNA were digested with restriction endonucleases according to the manufacturer's recommendations (Promega). DNA was separated by electrophoresis on agarose $0.6 \%$ gels in Tris-borate-EDTA buffer $(0.04 \mathrm{M}$ Tris-borate, $0.001 \mathrm{M}$ EDTA, $\mathrm{pH}$ 8.0) [26].

$P C R$ analysis. Insertion of $\operatorname{Tn} 916$ into the mutant strains was analysed by the use of transposon-specific tet $M$ gene primers [27] in a PCR assay. A $10-\mu \mathrm{l}(1 \mu \mathrm{g})$ portion of template DNA from $L$. monocytogenes WT, AAMU530, AAMU572 and E. faecalis CG110 (tet ${ }^{\mathrm{r}}$ ) was used for amplification in a total volume of $100 \mu \mathrm{l}$ in a Deltacycler I system (Ericomp, San Diego, CA, USA). The optimal PCR reaction mixture contained 100 pmol of each primer (left: 5' TTGATGCCCTTTTGGAATC 3'; right: 5' ACTGCATTCCACTTCCCAAC $3^{\prime}$ ), $40 \mathrm{mM}$ dNTPs, $10 \mu \mathrm{l}$ of $10 \times$ reaction buffer, 5 units of Taq polymerase (Sigma) and $10 \mu \mathrm{l}$ of mineral oil. Initial denaturation at $94^{\circ} \mathrm{C}$ for $5 \mathrm{~min}$ was followed by 30 cycles of $94^{\circ} \mathrm{C}, 2 \mathrm{~min} ; 60^{\circ} \mathrm{C}, 2 \mathrm{~min}$ and $72^{\circ} \mathrm{C}, 2 \mathrm{~min}$. After final extension at $72^{\circ} \mathrm{C}$ for $10 \mathrm{~min}$, the samples were stored at $4^{\circ} \mathrm{C}$ until analysis. The PCR products were separated by electrophoresis in agarose $1.2 \%$ gel.

Southern hybridisation. Southern hybridisation was performed according to the procedure of Southern [28] with the Genius System (Boehringer Mannheim, Indianapolis, IN, USA). HindIII-digested chromosomal DNA was electrophoresed and transferred to a nylon membrane (ICN, Costa Mesa, CA, USA). Pre-hybridisation of the membrane was carried out at $68^{\circ} \mathrm{C}$. The transposon probe was made from the EcoRI restriction fragment $(18 \mathrm{~kb})$ of pAM120 which contains the $\operatorname{Tn} 916$ complete sequence [27]. The 18-kb fragment was purified from the agarose gel with a Prep-A-Gene DNA Purification System (BioRad), followed by nonradioactive random primed labelling with the Genius System $^{\mathrm{TM}}$ (Boehringer Mannheim). Hybridisation products were detected by the enzyme immuno-assay method.

\section{SDS-PAGE and Western blotting}

L. monocytogenes WT, AAMU530, AAMU572, BUG8 and LUT12 strains along with other Listeria spp. were grown in BHI broth with or without tetracycline $10 \mu \mathrm{g} / \mathrm{ml}$ for $18-24 \mathrm{~h}$ at $37^{\circ} \mathrm{C}$. Cellsurface proteins were extracted with SDS-PAGE sample solvent [29] according to the method described by Bhunia et al. [30]. Protein samples were analysed in polyacrylamide $8 \%$ gels [29]. After electrophoresis $(25 \mathrm{~mA}, 2 \mathrm{~h})$, proteins were transferred to Immobilon-P membranes (Millipore, Bedford, MA, USA) by means of an electroblotter (BioRad). The membranes were blocked with non-fat dry milk $5 \%$ for 2-12 h, probed with MAb-H7 (1 in 1000) and the colour was developed [30]. Simultaneously, duplicate gels were also stained with Coomassie Blue R250 or silver stain (BioRad).

\section{Adhesion assay}

L. monocytogenes WT and the mutants AAMU530 and AAMU572 were tested for their ability to adhere to Caco-2 monolayers [9]. Caco-2 cell monolayers in 24well tissue culture plates were washed three times with $20 \mathrm{mM}$ phosphate-buffered saline (PBS), pH 7.0, and resuspended with $0.4 \mathrm{ml}$ of tissue culture medium per well. The monolayers were infected with $0.1 \mathrm{ml}$ of test organisms $\left(\right.$ c. $1 \times 10^{8} \mathrm{cfu} /$ well $)$ and incubated at $37^{\circ} \mathrm{C}$ for $30 \mathrm{~min}$. Non-adherent bacteria were eliminated by washing five times with PBS. Washed Caco- 2 monolayers were treated with $0.5 \mathrm{ml}$ of Triton X-100 $0.5 \%$ for $10 \mathrm{~min}$ and the counts of adherent bacteria were determined by plating on $\mathrm{BHI}$ agar.

Adhesion of Listeria spp. to Caco-2 cells was also examined by Giemsa's stain. Plastic coverslips containing Caco-2 cell monolayers were transferred to 12well tissue culture plates, inoculated with test organisms as described above and incubated at $37^{\circ} \mathrm{C}$ for $30 \mathrm{~min}$. After being washed five times, the monolayers were appropriately stained with Giemsa's stain as described previously [14].

\section{Effect of MAbs of adhesion}

A $0.1-\mathrm{ml}$ portion of each $L$. monocytogenes and $L$. innocua culture was allowed to react with $0.035 \mathrm{ml}$ $(34 \mathrm{mg} / \mathrm{ml})$ of MAb EM-7G1 or $\mathrm{H} 7$ for $1 \mathrm{~h}$ at $37^{\circ} \mathrm{C}$. The antibody-coated bacterial suspensions were then added to Caco- 2 cells and incubated at $37^{\circ} \mathrm{C}$ for $30 \mathrm{~min}$ [31]. Caco-2 cells were washed three times, treated with Triton X-100 $0.5 \%$ and bacterial counts were determined.

\section{Cytotoxicity assay}

Cytotoxic effects of mutants AAMU530 and AAMU572 and WT strains were determined on a hybridoma Ped-2E9 cell line by trypan blue $(0.4 \%)$ staining and alkaline phosphatase (AP) release assay as reported previously $[21,32]$.

\section{Results}

\section{Characterisation of transconjugants}

Six broth mating experiments resulted in a total of 82 mutants, of which only two (AAMU530 and AAMU572) showed weak or no reaction with MAbH7, suggesting that these strains possibly lacked the $104-\mathrm{kDa}$ (p104) surface protein. Both strains were confirmed to be L. monocytogenes by API-Listeria 
assay and were haemolytic $\left(\mathrm{hly}^{+}\right)$and phospholipase C positive $\left(\mathrm{plc}^{+}\right)$.

PCR analysis of mutants with Tn916-specific primers revealed that AAMU530, AAMU572 and E. faecalis CG110 (positive control) gave a PCR product of $294 \mathrm{bp}$ (Fig. 1a). No PCR product was observed from L. monocytogenes WT strain (negative control). This result demonstrated the insertion of $\operatorname{Tn} 916$ into the chromosome of the AAMU530 and AAMU572 strains (Fig. 1a).

In Southern hybridisation, the $\operatorname{Tn} 916$ probe hybridised with two complementary fragments $(>12$ and $6 \mathrm{~kb})$ from the HindIII-digested chromosomal DNA of strains AAMU530 and AAMU572, thus confirming the single $\operatorname{Tn} 916$ insertion into the chromosome of the mutants (Fig. 1b) because transposon insertion in multiple sites would have generated more than two Tn916-probe-reactive bands. The extra, high mol.wt, faint bands in the AAMU530 and AAMU572 lanes were the products of incomplete digestion of the genomic DNA. Plasmid pAM120 (23.3 kb), harbouring $\operatorname{Tn} 916$, had a single HindIII restriction site and therefore, showed a single high mol.wt band. The additional light bands present in the lane were perhaps due to degradation of the plasmid during isolation or by prolonged enzymatic digestion. A genomic DNA preparation from strain WT did not show any hybridisation with the probe (Fig. 1b).

\section{Western blotting}

Western blotting with MAb-H7 indicated that the p104 protein was absent from strains AAMU530 and AAMU572, but was present in L. monocytogenes WT, BUG8 $(\triangle i n l A B)$, LUT12 $(\triangle a c t A)$ and revertant strains of AAMU530 and AAMU572 (Fig. 2c). Furthermore, the MAb also reacted with protein extracts from $L$. innocua, $L$. ivanovii, $L$. seeligeri and $L$. welshimeri, but had no reaction with $L$. grayi (Fig. 2b). Silver staining of SDS-PAGE gel showed that strain AAMU530 had a very faint band at $104 \mathrm{kDa}$, whereas no band was observed for strain AAMU572 at that position (Fig. 2a).

\section{Adhesion of listeria to Caco-2 cells}

Adhesion results (Table 1) demonstrated that strains AAMU530 and AAMU572 had only 10 and $6.3 \%$ adhesion to Caco- 2 cells, respectively, values significantly lower than the $100 \%$ of adhesion strain WT $(\mathrm{p} \leqslant 0.05)$. L. innocua also showed adhesion to Caco-2 cells, but less efficiently than $L$. monocytogenes WT strain. Giemsa's staining results exhibited similar patterns of adhesion to the Caco-2 cells (data not shown). L. monocytogenes WT, showed 50\% adhesion when coated with MAb-H7, which was significantly lower than that of $L$. monocytogenes cells treated with the control MAb EM-7G1 (Table 1). On the other

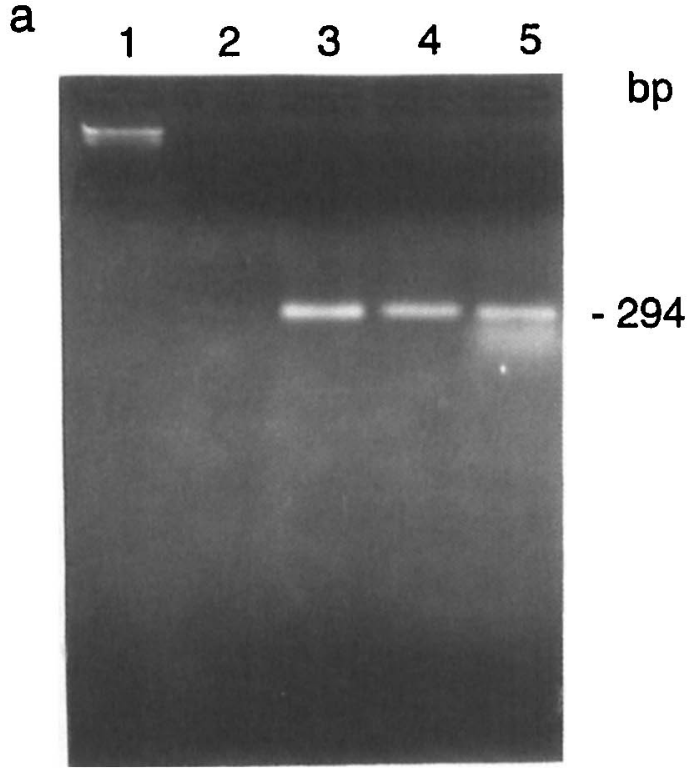

b

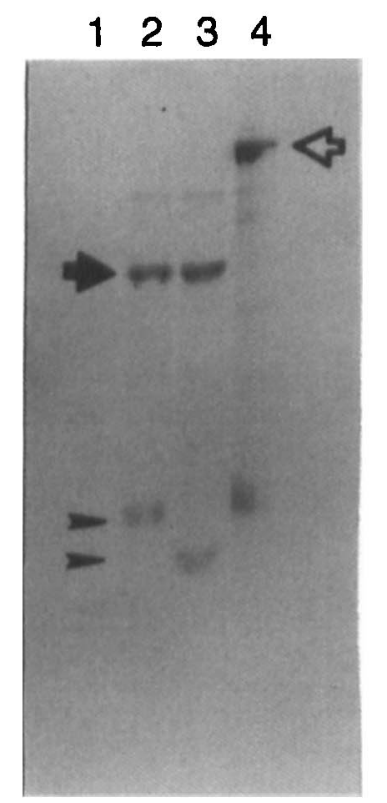

Fig. 1. (a) PCR confirmation of $\operatorname{Tn} 916$ insertion in $L$. monocytogenes mutant strains with tetM gene-specific primers. Lane 1, DNA standard; 2, L. monocytogenes WT; 3, AAMU530; 4, AAMU572; 5, E. faecalis CG110 carrying Tn916. (b) Southern hybridisation of HindIIIdigested genomic DNA from L. monocytogenes mutant strains and plasmid pAM120 from E. coli CG120 harbouring Tn916 with an 18 -kb Tn916 probe. Lanes 1, L. monocytogenes WT; 2, AAMU530; 3, AAMU572; 4, plasmid pAM120. Tn916 probe hybridised with two fragments of $>12(\Delta)$ and $6 \mathrm{~kb}(\vec{C})$ from AAMU530 (lane 2) and AAMU572 (lane 3) and one major band (4) from pAM120 linearised $(23.3 \mathrm{~kb})$ with HindIII (lane 4$)$. The other bands in lane 4 are possibly the nonspecific breakdown products of enzymic digestion.

hand, L. innocua cells treated with MAb-H7 had $45 \%$ and cells treated with EM-7G1 had 77\% adhesion to Caco-2 cells; however, these differences in adhesion were not statistically significant at $\mathrm{p} \leqslant 0.05$ (Table 1). 
a

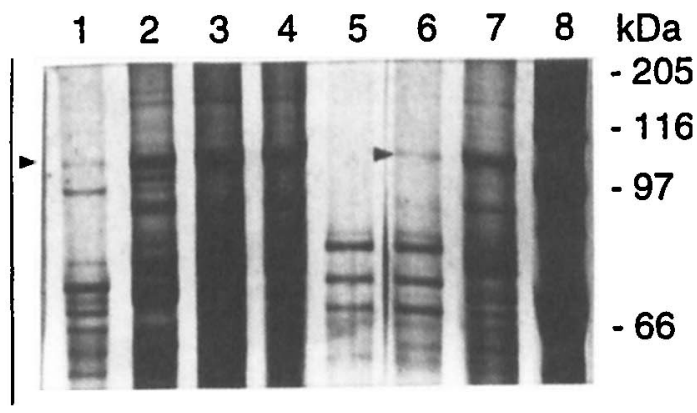

b
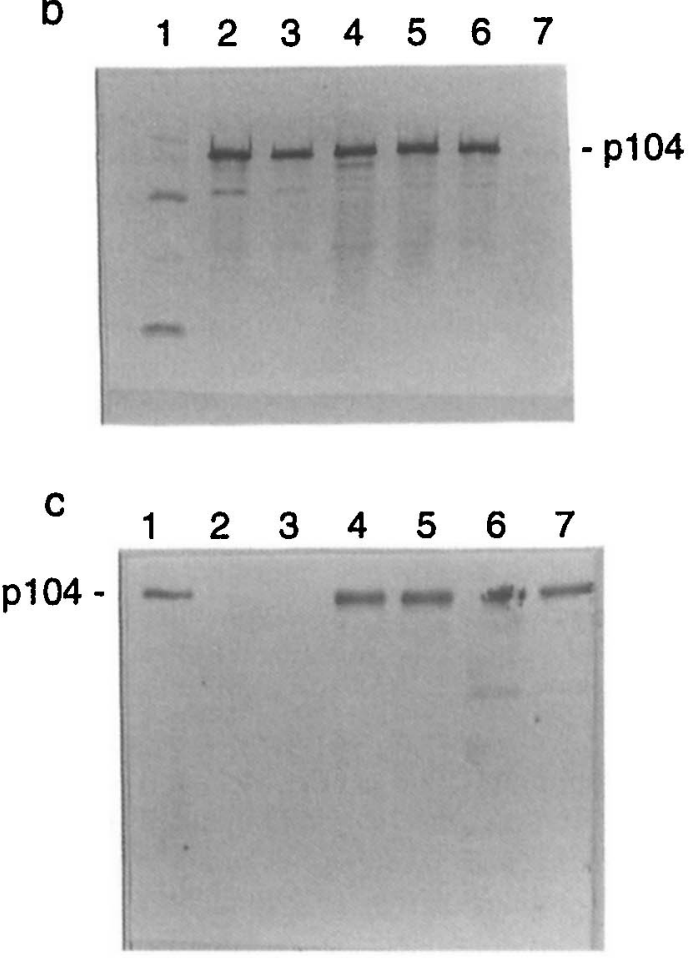

Fig. 2. (a) Silver-stained SDS-PAGE gel of cell-surface proteins from $L$. monocytogenes strains. Lane 1, LUT12$\triangle a c t A ; 2$, BUG8- $\triangle \operatorname{inl} A B ; 3$, revertant AAMU572; 4, revertant AAMU530; 5, AAMU572- $\Delta p 104 ; \quad 6$, AAMU 530- $\Delta$ p 104; 7, WT; 8, mol.wt standard. Arrowhead in lane 6 indicates the presence of weak p104 protein band. (b) Western blot analysis of proteins from various Listeria species with MAb-H7. Lane 1, mol. wt standard; 2, L. monocytogenes WT; 3, L. innocua; 4, L. ivanovii; $\mathbf{5}$, L. seeligeri; $\mathbf{6}, L$. welshimeri, 7, L. grayi. (c) Western blot analysis of cell-surface proteins from $L$. monocytogenes strains with MAb-H7. Lane 1, WT; 2, AAMU530; 3, AAMU572; 4, BUG8; 5, LUT12; 6, revertant AAMU530; 7, revertant AAMU572. MAb showed no reaction with proteins from the mutant AAMU530 and AAMU572 strains.

\section{Cytotoxicity profile of mutant strains}

In the hybridoma cell viability assay, the percentage cell death for $L$. monocytogenes strains WT, AAMU530, AAMU572 and L. innocua was calculated to be $84,70,54$ and $6 \%$, respectively (Fig. 3). Similarly, in the AP assay, strains AAMU530 and AAMU572 induced AP releases of 16 and $15 \%$ respectively, which was significantly lower than the
Table 1. Effect of mutation ( $\operatorname{Tn} 916)$ and MAbs on adhesion of Listeria species to Caco-2 cells

\begin{tabular}{|c|c|c|}
\hline \multirow[b]{2}{*}{ Organisms } & \multicolumn{2}{|l|}{ Adhesion } \\
\hline & $\begin{array}{l}\text { Average cfu/well* } \\
\log _{10} \text { mean cfu (SD) }\end{array}$ & $\begin{array}{c}\text { Adhesion } \\
(\%)^{\dagger}\end{array}$ \\
\hline \multicolumn{3}{|l|}{ L. monocytogenes } \\
\hline F4244 (WT) & $\begin{array}{l}1.04 \times 10^{6} \\
6.00(0.12)\end{array}$ & 100 \\
\hline AAMU530 $(\Delta p 104: \operatorname{Tn} 916)$ & $\begin{array}{l}1.04 \times 10^{5} \\
5.00(0.09)\end{array}$ & 10 \\
\hline AAMU572 $(\Delta p 104: \operatorname{Tn} 916)$ & $\begin{array}{l}6.6 \times 10^{4} \\
4.81(0.18)\end{array}$ & 6.3 \\
\hline $\mathrm{F} 4244+\mathrm{EM}^{-7} \mathrm{GI}^{\ddagger}$ & $\begin{array}{l}1.19 \times 10^{6} \\
6.07(0.02)\end{array}$ & 100 \\
\hline $\mathrm{F} 4244+\mathrm{MAb}-\mathrm{H} 7^{\ddagger}$ & $\begin{array}{l}5.19 \times 10^{5} \\
5.07(0.09)\end{array}$ & 50 \\
\hline \multicolumn{3}{|l|}{ L. innocua } \\
\hline F4248 & $\begin{array}{l}4.11 \times 10^{4} \\
4.61(0.36)\end{array}$ & 100 \\
\hline $\mathrm{F} 4248+\mathrm{EM} \mathrm{G} 1^{\ddagger}$ & $\begin{array}{l}3.18 \times 10^{4} \\
4.50(0.36)\end{array}$ & 77 \\
\hline $\mathrm{F} 4244+\mathrm{MAb}-\mathrm{H} 7^{\ddagger}$ & $\begin{array}{l}1.86 \times 10^{4} \\
4.26(0.47)\end{array}$ & 45 \\
\hline
\end{tabular}

${ }^{*} \mathrm{Cfu} /$ well is an average of six replicates from three experiments. ${ }^{\dagger}$ Percentage adhesion calculations were based on the total adhesion by $L$. monocytogenes or $L$. innocua wild-type strains without any treatments using average cfu/well values.

${ }^{\ddagger} \mathrm{MAb}$ EM-7G1 and $\mathrm{H} 7$ are specific for $66-\mathrm{kDa}$ and $104-\mathrm{kDa}$ proteins, respectively, and belong to the IgG1 subclass.

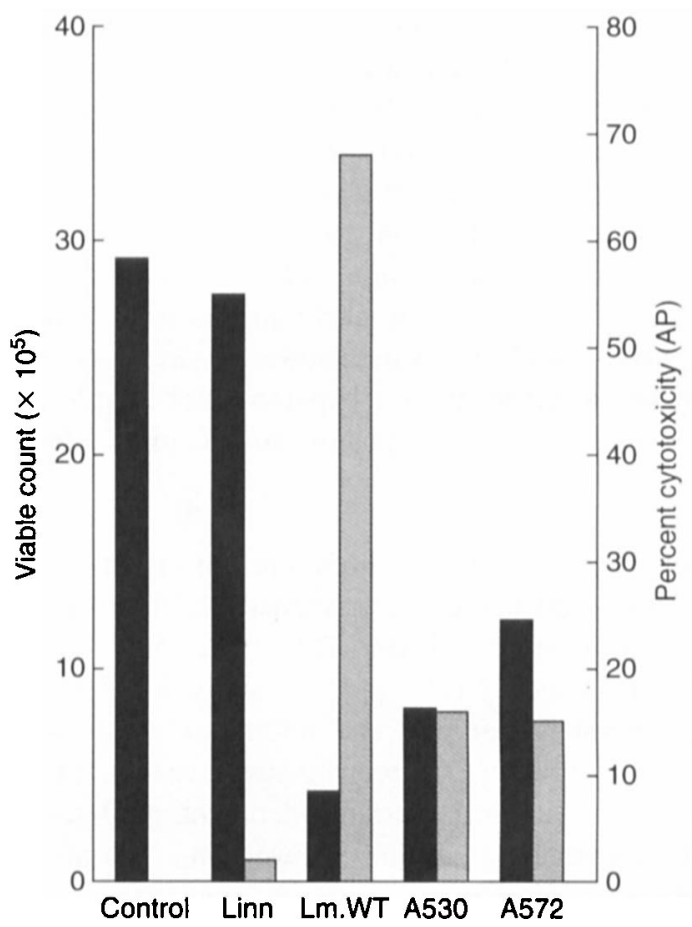

Fig. 3. Cytotoxicity of $L$. monocytogenes mutant strains on a hybridoma B-lymphocyte line (Ped-2E9). Ped-2E9 cells were treated with PBS (control), L. innocua (Linn) and $L$. monocytogenes strains WT (Lm.WT), AAMU530 (A530) and AAMU572 (A572) for $5 \mathrm{~h}$. Cytotoxic effects were determined by counting viable cells $(\square)$ after trypan blue staining or by calculating percentage alkaline phosphatase (甍) release from Ped-2E9 cells [32]. Percentage cytotoxicity was determined based on the total alkaline phosphatase (AP) release from Triton-Xtreated Ped-2E9 cells. 
$68 \%$ released by $L$. monocytogenes WT $(\mathrm{p} \leqslant 0.05)$. In contrast, $L$. innocua induced only $2 \%$ AP release (Fig. 3).

\section{Discussion}

Adhesion and invasion of professional and nonprofessional phagocytic cells by listeria are crucial steps in the pathogenesis of infection. L. monocytogenes penetrates certain mammalian cells with the help of internalin proteins (In1A and In1B) or may induce its own internalisation by activating host cell signal transduction pathways $[33,34]$. Internalin-mediated entry is believed to be initiated through binding of the leucine-rich repeat region of internalin with a Ecadherin receptor on mammalian cells through a zipper mechanism $[12,35]$.

While many studies have explored the mechanisms of internalisation, only limited information is available as to the mechanisms of listeria adhesion to mammalian cells. Adhesion is an important key step in listeria pathogenesis, which is believed to be a complex process involving many cell-surface molecules [36], whose specific function(s) are not well understood. In general, adhesion properties in listeria are believed to be not only associated with pathogenic L. monocytogenes or $L$. ivanovii, but also with non-pathogenic $L$. innocua, L. welshimeri or L. seeligeri. To date, several cell surface molecules have been implicated in the adhesion of listeria to host cells. As discussed above, internalin [6] may be involved in adhesion; however, this protein is present only in $L$. monocytogenes and not in other Listeria spp. ActA protein, which is primarily responsible for bacterial motility inside the host cell cytoplasm, was shown to help L. monocytogenes attachment to a heparan sulphate proteoglycan receptor in macrophage and Chinese hamster ovary $(\mathrm{CHO})$ cells [8].

Another surface protein $\mathrm{p} 60$, present in all Listeria spp., was reported to be responsible for adhesion to and invasion of fibroblast (3T6) cells, but not to the epithelial (Caco-2) cells [14]. A study by Hess et al. [15] suggested that p60 and internalin possibly acted in concert during L. monocytogenes invasion. Their invivo study with an internalin-deficient, p60-secreting L. monocytogenes strain showed no variation in adhesion or invasion of mouse intestinal cells and consequently they concluded that there might be additional factor(s) responsible for adhesion and invasion by L. monocytogenes. Cowart et al. [9] indicated that $L$. monocytogenes surface carbohydrate molecules, such as $\alpha$-D-galactose, initiate adhesion to hepatocarcinoma (HepG-2) cells via a galactose receptor. Recently, Maganti et al. [10] showed that $\mathrm{N}$-acetylneuraminic acid was also involved in adhesion to murine peritoneal macrophages. Meyer et al. [18] and Bunduki et al. [19] showed that L. monocyto- genes, L. innocua, L. ivanovii, L. seeligeri and $L$. welshimeri show varying degrees of adhesion to intestinal epithelial cells. However, there is no report on identification or characterisation of the bacterial factors responsible for such adhesion. Summarising the above information leads to the conclusion that several factor(s) may possibly be involved in listeria adhesion to mammalian cells.

This study reports the identification of a surface protein, p104, that is involved in the adhesion of Listeria spp. to Caco-2 cells. Two mutant strains, AAMU530 and AAMU572, were developed with the aid of a conjugative transposon ( $\operatorname{Tn} 916)$. These strains were haemolytic $\left(\mathrm{hly}^{+}\right)$and phospholipase C-positive $\left(\mathrm{plc}^{+}\right)$and showed no reaction with a p104-specific MAb-H7 in Western immunoblot, suggesting that these strains lacked p104 expression. The complete absence of p104 expression in strain AAMU572 was also confirmed by silver staining of SDS-PAGE; however, a faint $104-\mathrm{kDa}$ band was visible upon silver staining for AAMU530 proteins. Lack of expression of p104 is due to the insertion of $\operatorname{Tn} 916$ into the structural gene, which was confirmed by PCR and Southern hybridisation (Fig. 1). Furthermore, Southern hybridisation results indicated that $\operatorname{Tn} 916$ had been inserted in only a single locus in the chromosome of each of the mutants. Thus, the mutant strains obtained in this study acquired a site-specific mutation for p104 without interference to the other structural or physiological genes. Strains AAMU530 and AAMU572 lost Tn916 when cultured in antibiotic-free media and resulting revertant strains expressed p104 proteins similarly to strain WT (Fig. 2). This study further confirmed the insertion of $\operatorname{Tn} 916$ in the chromosome of mutant strains.

Western blotting of protein extracts from internalin (BUG8)- and ActA (LUT12)-deficient strains indicated that these two strains reacted with $\mathrm{MAb}-\mathrm{H} 7$, suggesting that p104 is distinct from internalin and ActA (Fig. 2c). The present study also examined the expression of p104 in other Listeria spp. by Western blotting and showed that this protein is present in $L$. monocytogenes, L. innocua, L. ivanovii, L. seeligeri and L. welshimeri, but not in L. grayi (Fig. 2b). This study further suggested that unlike the internalin and ActA proteins, p104 is present in both pathogenic and non-pathogenic Listeria spp.

The adhesion assay data illustrated that the mutants AAMU530 and AAMU572 had significantly reduced adherence to Caco- 2 cells compared with the parent strain (Table 1). However, as the mutant strains ( $\Delta$ p 104) still showed some adhesion to Caco-2 cells, it is conceivable that other factors are possibly involved in the adhesion process besides p104. Among the mutants, strain AAMU530 showed relatively higher adhesion (10\%) than strain AAMU572 (6.3\%) $(p \leqslant 0.05)$. This discrepancy may be caused by the 
partial expression of p104 in AAMU530 as evidenced in the silver-stained gel (Fig. 2a). Studies with MAbs revealed that $\mathrm{MAb}-\mathrm{H} 7$ (specific for p104) also partially inhibited the adhesion of wild-type $L$. monocytogenes and $L$. innocua to Caco-2 cells. On the other hand, an isotype control, MAb EM-7G1 (specific for the 66-kDa surface protein), did not interfere with adhesion. Adhesion of $L$. innocua to Caco-2 cells without antibody treatment was also studied and it was less than that of L. monocytogenes WT. Bunduki et al. [19] also observed the lesser adherence of $L$. innocua to primary intestinal endothelial cells. These findings strongly suggest that p104, a previously unreported protein, plays an important role in the adhesion of $L$. monocytogenes to Caco-2 cells. Furthermore, pl04 is also possibly responsible for adhesion of $L$. innocua to Caco-2 cells. Although not tested, p104 may act as an adhesion factor in other Listeria spp. including $L$. ivanovii, L. welshimeri and L. seeligeri, as they also express p104 (Fig. 2b).

Although the $\Delta p 104$ mutant strains were $\mathrm{hly}^{+}$and $\mathrm{plc}^{+}$, cytotoxicity data indicated that these mutants exhibited a significantly reduced virulence, suggesting that the absence of p104 in these mutants may have resulted in reduced adherence, and thus a lowered cytotoxic effect. In a separate experiment, the p104specific MAb also inhibited the cytotoxic effect of $L$. monocytogenes on Caco-2 and Ped-2E9 cells (data not shown). Again, the reduced cytotoxic effect may be due to the blocking of p104 by MAb-H7, leading to a decrease in adhesion of $L$. monocytogenes and thus interfering with the cytotoxic effect on mammalian cells. Collectively, these results suggest that p104 is an important adhesion factor in $L$. monocytogenes and possibly in other Listeria spp., and is responsible for adhesion to intestinal Caco-2 cells. Presumably, p104 acts in concert with other molecules to ensure attachment to mammalian cells.

We sincerely thank P. Cossart, Pasteur Institute, Paris, for providing L. monocytogenes strains BUG8 and LUT12, and also D. Clewell, University of Michigan, for providing the Enterococcus faecalis CG110 and Escherichia coli CG120 strains. We also thank R. Zhaorchak, Research Genetics, Huntsville, AL, for providing the PCR primers and helpful discussions and A. Zipf and C. Chawan for critical review of the manuscript. This project was partially funded by grants from the US Department of Education for strengthening the $\mathrm{PhD}$ programme in Food Science and from the USDA CSREES programme.

Published with the approval of the Director of the Agricultural Experiment Station, Alabama A \& M University, Normal, AL, USA.

\section{References}

I. Gellin BG, Broome CV. Listeriosis. JAMA 1989; 261: 13131320.

2. Salamina G, Dalle Donne E, Niccolini A et al. A foodborne outbreak of gastroenteritis involving Listeria monocytogenes. Epidemiol Infect 1996; 117: 429-436.

3. Marco AJ, Prats N, Ramos JA et al. A microbiological, histopathological and immunohistological study of the intra- gastric inoculation of Listeria monocytogenes in mice. $J$ Comp Pathol 1992; 107: 1-9.

4. Pron B, Boumaila C, Jaubert F et al. Comprehensive study of the intestinal stage of listeriosis in a rat ligated ileal loop system. Infect Immun 1998; 66: 747-755.

5. Alvarez-Dominguez $\mathrm{C}$, Carrasco-Marin E, Leyva-Cobian $\mathrm{F}$. Role of complement component $\mathrm{Clq}$ in phagocytosis of Listeria monocytogenes by murine macrophage-like cell lines. Infect Immun 1993; 61: 3664-3672.

6. Gaillard J-L, Berche P, Frehel C, Gouin E, Cossart P. Entry of $L$. monocytogenes into cells is mediated by internalin, a repeat protein reminiscent of surface antigen from gram-positive cocci. Cell 1991; 65: 1127-1141.

7. Lingnau A, Domann E, Hudel $\mathrm{M}$ et al. Expression of the Listeria monocytogenes EGD inlA and inlB genes, whose products mediate bacterial entry into tissue culture cell lines, by PrfA-dependent and -independent mechanisms. Infect Immun 1995; 63: 3896-3903.

8. Alvarez-Domínguez C, Vázques-Boland J-A, Carrasco-Marín E, Lopez-Mato P, Leyva-Cobián F. Host cell heparan sulfate proteoglycans mediate attachment and entry of Listeria monocytogenes, and the Listerial surface protein ActA is involved in heparan sulfate receptor recognition. Infect Immun 1997; 65: 78-88.

9. Cowart RE, Lashmet J, McIntosh ME, Adams TJ. Adherence of a virulent strain of Listeria monocytogenes to the surface of a hepatocarcinoma cell line via lectin-substrate interaction. Arch Microbiol 1990; 153: 282-286.

10. Maganti S, Pierce MM, Hoffmaster A, Rodgers FG. The role of sialic acid in opsonin-dependent and opsonin-independent adhesion of Listeria monocytogenes to murine peritoneal macrophages. Infect Immun 1998; 66: 620-626.

11. Dramsi S, Dehoux $P$, Lebrun $M$, Goossens $P$, Cossart $P$. Identification of four new members of the internalin multigene family of Listeria monocytogenes EGD. Infect Immun 1997; 65: 1615-1625.

12. Mengaud J, Ohayon H, Gounon P, Mege RM, Cossart P. Ecadherin is the receptor for internalin, a surface protein required for entry of $L$. monocytogenes into epithelial cells. Cell 1996; 84: 923-932.

13. Engelbrecht F, Chun S-K, Ochs C et al. A new PrfA-regulated gene of Listeria monocytogenes encoding a small, secreted protein, which belongs to the family of internalins. Mol Microbiol 1996; 21: 823-837.

14. Bubert A, Kuhn M, Goebel W, Kohler S. Structural and functional properties of the p60 proteins from different Listeria species. J Bacteriol 1992; 174: 8166-8171.

15. Hess J, Gentschev I, Szalay G et al. Listeria monocytogenes p60 supports host cell invasion by and in vivo survival of attenuated Salmonella typhimurium. Infect Immun 1995; 63: 2047-2053.

16. Tang P, Rosenshine I, Finlay BB. Listeria monocytogenes, an invasive bacterium, stimulates MAP kinase upon attachment to epithelial cells. Mol Biol Cell 1994; 5: 455-464.

17. Velge $P$, Bottreau E, Kaeffer B, Yurdusev N, Pardon P, Langendonck NV. Protein tyrosine kinase inhibitors block the entries of Listeria monocytogenes and Listeria ivanovii into epithelial cells. Microb Pathog 1994; 17: 37-50.

18. Meyer DH, Bunduki $M$, Beliveau $C M$, Donnelly $C W$. Differences in invasion and adherence of Listeria monocytogenes with mammalian gut cells. Food Microbiol 1992; 9: 115-126.

19. Bunduki MC, Beliveau CM, Donnelly CW. Examination of attachment and phagocytic uptake of Listeria species by mammalian intestinal cells. Food Microbiol 1993; 10: 507-516.

20. Bhunia AK, Westbrook DG, Story R, Johnson MG. Monoclonal antibody mediated blockage of Listeria adhesion to mammalian cells. Annual Meeting of the American Society for Microbiology Washington, DC. 1995; Abstract P-79: 396.

21. Bhunia AK, Steele PJ, Westbrook DG, Bly LA, Maloney TP, Johnson MG. A six-hour in vitro virulence assay for Listeria monocytogenes using myeloma and hybridoma cells from murine and human sources. Microb Pathog 1994; 16: 99-110.

22. Bhunia AK, Johnson MG. Monoclonal antibody specific for Listeria monocytogenes associated with 66-kilodalton cell surface antigen. Appl Environ Microbiol 1992; 58: 1924-1929.

23. Gawron-Burke C, Clewell DB. Regeneration of insertionally inactivated streptococcal DNA fragments after excision of 
transposon Tn916 in Escherichia coli: strategy for targeting and cloning of genes from gram-positive bacteria. $J$ Bacteriol 1984; 159: 214-221.

24. Kathariou S, Metz $\mathrm{P}$, Hof $\mathrm{H}$, Goebel W. Tn916-induced mutations in the hemolysin determinant affecting virulence of Listeria monocytogenes. J Bacteriol 1987; 169: 1291-1297.

25. Schwan WR, Demuth A, Kuhn M, Goebel W. Phosphatidylinositol-specific phospholipase $\mathrm{C}$ from Listeria monocytogenes contributes to intracellular survival and growth of Listeria innocua. Infect Immun 1994; 62: 4795-4803.

26. Sambrook J, Fritsch EF, Maniatis T. Molecular cloning: a laboratory manual, 2nd edn. Cold Spring Harbor, NY, Cold Spring Harbor Laboratory Press, 1989.

27. Flannagan SE, Zitzow LA, Su YA, Clewell DB. Nucleotide sequence of the $18-\mathrm{kb}$ conjugative transposon $\mathrm{Tn} 916$ from Enterococcus faecalis. Plasmid 1994; 32: 350-354.

28. Southern EM. Detection of specific sequence among DNA fragments separated by gel electrophoresis. $J$ Mol Biol 1975 ; 98: $503-517$

29. Laemmli UK. Cleavage of structural proteins during the assembly of the head of bacteriophage T4. Nature $1970 ; 227$ $680-685$.
30. Bhunia AK, Ball PH, Fuad AT, Kurz BW, Emerson JW, Johnson MG. Development and characterization of a monoclonal antibody specific for Listeria monocytogenes and Listeria innocua. Infect Immun 1991; 59: 3176-3184.

31. Doig P, Sastry PA, Hodges RS, Lee KK, Paranchych W, Irvin RT. Inhibition of pilus-mediated adhesion of Pseudomonas aeruginosa to human buccal epithelial cells by monoclonal antibodies directed against pili. Infect Immun 1990; 58: $124-130$.

32. Bhunia AK, Westbrook DG. Alkaline phosphatase release assay to determine cytotoxicity for Listeria species. Lett Appl Microbiol 1998; 26: 305-310.

33. Ireton $\mathrm{K}$, Payrastre $\mathrm{B}, \mathrm{Chap} \mathrm{H}$ et al. A role of phosphoinositide 3-kinase in bacterial invasion. Science 1996; 274: 780-782

34. Finlay BB, Cossart P. Exploitation of mammalian host cell functions by bacterial pathogens. Science 1997; 276: 718-725.

35. Lecuit $M$, Ohayon $H$, Braun L, Mengaud J, Cossart $P$. Internalin of Listeria monocytogenes with an intact leucinerich repeat region is sufficient to promote internalization. Infect Immun 1997; 65: 5309-5319.

36. Bhunia AK. Antibodies to Listeria monocytogenes. Crit Rev Microbiol 1997; 23: 77-107. 